\author{
Maria Inês Amarante \\ Pontifícia Universidade Católica de São Paulo
}

\title{
Guerrilheiras da palavra: as mulheres no rádio em Timor-Leste
}

\begin{abstract}
Resumo: Este artigo, recorte da tese de doutorado da autora, mostra o papel social do rádio em Timor-Leste, bem como o protagonismo das mulheres comunicadoras, outrora guerrrilheiras, desde a independência do país. Embora a presença feminina na mídia timorense seja ainda bastante tímida e haja necessidade de transpor inúmeras barreiras, inclusive o uso da língua portuguesa, elas enfatizam a relevância dessa participação e o reconhecimento do trabalho radiofônico nos espaços recentemente conquistados. Entre reflexões sobre a voz e a palavra em ambientes de "oralidade mediatizada", vão se revelando aspectos culturais de um povo que busca adequar-se a uma nova realidade sem abdicar de suas tradições. A pesquisa fol realizada em campo, entre 2005 e 2006, e materializou-se através de levantamentos documental, bibliográfico e entrevistas (história de vida e relatos testemunhais).
\end{abstract}

Palavras-chave: rádio; memória feminina; voz e oralidade; língua portuguesa; Timor-Leste.

Copyright @ 2013 by Revista Estudos Feministas.

'Antes da chegada dos portugueses, no século XVI, Timor conheceu inúmeras invasões que deixaram traços de misturas étnicas e que formam um panorama complexo de culturas sobrepostas (Armando Marques GUEDES, 2002, p. 2): indianos ali transitaram até o século XII; mercadores árabes passaram a partir do século XIII e, no início do século XVI, povos chineses, malaios e javaneses já visitavam a ilha atraídos pelo comércio de sândalo. Os africanos vieram como escravos e milicianos junto à colonização portuguesa. No século XX, o país foi ocupado pelos japoneses durante a Segunda Grande Guerra Mundial; invadido pelos australianos e, de 1975 a 1999, esteve sob o jugo indonésio.

2 Reinaldo BORGES, 2003, p. 17.

3 José MATTOSO, 2005, p. 123.

\section{Introdução}

Timor-Leste foi a primeira nação a despontar no século XXI, deixando para trás as sombras de um passado colonial e de ocupações que marcaram profundamente o seu povo, tanto do ponto de vista linguístico como no âmbito sociocultural. ${ }^{1} \mathrm{O}$ rádio esteve presente em momentos decisivos dessa história, registrando a violência que ceifou tantas vidas e as lutas de resistência heroicas. ${ }^{2}$ Ele é o meio de comunicação mais popular e o que traz uma maior perspectiva de desenvolvimento para a população do meio rural, que representa $80 \%$ de habitantes do país.

Em quase todas as fotografias de bases guerrilheiras presentes na obra A Dignidade, ${ }^{3}$ de José Mattoso, o aparelho de rádio sempre aparece em destaque, indicando como a escuta do veículo foi relevante nas estratégias de mobilização popular.

Encontra-se registrado, em documentos sobre a resistência timorense (2004), ${ }^{4}$ que a mulher, mãe e companheira, assumiu pesadas responsabilidades durante a ocupação indonésia, participando em várias frentes: na condução da 
${ }^{5}$ Luis CARDOSO, 2002, p. 96. - Segundo estudos do linguista Geoffrey Hull (2001), há 16 línguas distintas em Timor-Leste; porém, muitas delas estão subdivididas em dialetos locais e, no país todo, encontra-se em torno de 30 línguas e dialetos diferentes. Em 2002, foram definidas como línguas oficiais o português (língua instrucional e administrativa), que havia sido proscrito pelos indonésios em proveito do bahasa indonésio (ou língua indonésia), e o tétum, falado originalmente por cerca de $80 \%$ da população e que, apesar de suas variações, funciona como uma língua franca.

7 Regulamento UNTAET 2001/15, do governo de transição.

${ }^{8}$ As estradas que serpenteiam as encostas das montanhas timorenses apresentam inúmeros perigos como desabamentos frequentes e transportes coletivos precários, daí a importância dos meios de comunicação como o rádio. Estudos realizados pelo Instituto Internacional Republicano (IRI), em 2003, demonstram que a vasta maioria da população de TimorLeste $(63 \%)$ obtém informação política a partir da rádio, enquanto um estudo de 2002, conduzido pela Fundação Ásia, aponta para $67 \%$. - São elas, Rádio Komunidade Café-Ermera; Rádio Komunidade Manatuto, RC Suai, Rádio Loriko Lian, Rádio Komunidade Same: Rádio Komunidade Maliana, Rádio Komunidade Atoni Lifau, Oecussi; Rádio Komunidade Hai Husar Aileu, Rádio Komunidade Tokodede Liquiça, Rádio Komunidade Povu Viqueque, Rádio Komunidade Baucau, Rádio Komunidade Los palos, Rádio Komunidade Hakambia, Rádio Klibur, reunidas através do Centro Rádio Comunidade (CRC). resistência, na luta armada, no comando de operações, na comunicação ou no contato com a Frente Clandestina; porém, seus testemunhos são ainda escassos. As jovens que lutaram pela independência e tiveram participação política na reconquista do território tornaram-se mulheres. Muitas abraçaram uma carreira, casaram-se, tiveram filhos e algumas delas, hoje, são vozes mediatizadas que atuam nos meios de comunicação, principalmente no rádio, como jornalistas ou apresentadoras de jornais, mantendo o idealismo que sempre permeou suas vidas. Diariamente divulgam preciosas informações, reafirmando a existência de outra realidade profissional. Ativas no Parlamento, na mídia ou nas escolas, se deslocam no país e para o exterior, contribuindo para um debate de ideias que têm marcado a vida de outras mulheres de regióes distantes da capital e que vão se tornando políticas públicas. O 25 de abril de 1974, data histórica da "Revolução dos Cravos" em Portugal, repercutiu nas colônias portuguesas desencadeando inúmeras lutas independentistas. Em TimorLeste, surgiram as primeiras organizações nacionalistas, e as notícias dos movimentos de libertação foram divulgadas no rádio sob a forma de comunicados da Junta de Salvação Nacional, como lembra o escritor Luis Cardoso. ${ }^{5}$ Contudo, no ano seguinte, o país foi invadido pelos indonésios, que, durante 25 anos, controlaram a mídia oficial e perseguiram os meios que serviam o movimento de resistência. Uma rádio clandestina das Forças Armadas de Libertação Nacional de Timor-Leste (FALINTIL) sobreviveu até o final de 1999 e hoje divulga músicas e notícias. De 1999 a 2002, período de transição pós-referendum, quando o país esteve sob o comando da Administração Transitória das Nações Unidas para Timor-Leste (UNTAET), e antes de haver definição das línguas oficiais, ${ }^{6}$ a Rádio UNTAET FM realizava transmissões em quatro idiomas, a saber: inglês, indonésio, português e tétum. Conforme a Lei das Telecomunicações vigente nesse período e atualizada após $2002,{ }^{7}$ estão previstos no país três tipos de serviços: o público, o privado/comercial e o comunitário; porém, não existem rádios privadas em Timor-Leste e desconhece-se a publicidade no veículo.

Atualmente, o rádio encontra-se presente em vários pontos do território e tem audiência em localidades distantes e de difícil acesso. ${ }^{8}$ Há 14 emissoras comunitárias, ${ }^{9}$ que emitem em FM cobrindo quase todo o país. As transmissões são feitas, principalmente, em língua tétum e em línguas regionais, e recentemente foi introduzido o português em parte da programação. A maioria delas foi instalada entre 2001 e 2003, através de projetos financiados por organismos internacionais, e dependem da colaboração de voluntários. Notamse, porém, muitos entraves para que funcionem adequadamente, sobretudo no que se refere à formação dos comunica- 
${ }^{10}$ Maria Inês AMARANTE, 2006, p. 171.

11 AMARANTE, 2006, p. 172.

12 Entrevista realizada em 31 de maio de 2009, em São Paulo/ Brasil.

${ }^{13}$ Telemóvel designa o telefone celular. dores, manutenção das estruturas, organização interna e o idioma a ser utilizado, lembra Amarante. ${ }^{10}$ Há também rádios em inglês, emissoras de ondas médias, uma emissora evangélica; serviços internacionais da RDP portuguesa, da BBC inglesa e a emissora oficial, a Rádio Timor Leste, da Rede de Rádio e Televisão Timor Leste (RTTL), presente em 12 dos 13 distritos do país. Pode-se, igualmente, captar emissoras estrangeiras em FM da Austrália e de Portugal. ${ }^{11}$ De 2006 a 2010, foi oferecido um serviço de radiodifusão na Universidade Nacional de Timor-Leste (UNTL), com o apoio da Embaixada do Brasil: a Rádio Timor, onde foram emitidos diversos programas para a difusão da língua portuguesa.

Poucas pessoas, no entanto, tiveram a oportunidade de conhecer um meio de comunicação tão original como a Irmã Vera Lúcia Palermo. ${ }^{12}$ Do tempo em que realizou trabalhos comunitários em Laclubar, de 2005 a 2008, região montanhosa onde a população vive quase isolada, ela guardou na memória a forma como eram transmitidas as mensagens:

O chefe de suco para dar o recado para as pessoas manda alguém subir em cima do telhado e anunciar - e o povo escuta. De vez em quando, a gente via um homem falando em cima do telhado e eles escutam. Lá só quem tinha TV era o pároco [...]. Quem traz notícias de Dili são as angunas - notícias de boca - de Dili, de Manatuto. Lá, não podemos receber telefone. Mas para o telemóvel, ${ }^{13}$ subíamos nas montanhas de Maubere para captar.

Esse meio performático de emissão da voz convive harmoniosamente com as ondas sonoras do rádio, apesar das dificuldades técnicas da recepção, como bem observa a religiosa brasileira:

Eu passei muito tempo sem ver luz. Depois, das seis da tarde até meia-noite, um dia sim, dia não. Eles fazem umas antenas lá do jeito deles e ouvem rádio. De Portugal, da Indonésia, sobretudo, e a timorense. Quando teve o atentado com o Ramos Horta, a aldeia ouviu no rádio. Nós nunca conseguimos fazer essa antena. Agora, os timorenses sabem tudo pelo rádio. De $T V$, eles não têm e os que têm assistem filmes da Indonésia.

Nas feiras livres, a oferta de pequenos transmissores à pilha é significativa, e a população ouve rádio nos precários transportes coletivos: as microletes, na cidade, ou as angunas, um tipo de caminhão, adaptado com bancos, que percorre as montanhas. Além de músicas cantadas por intérpretes locais, ouvem-se canções mais recentes do repertório brasileiro, geralmente sertanejas ou regionais e muitas dos anos de 1970, da jovem guarda, dando a impressão de que o 
${ }^{14}$ CARDOSO, 2002, p. 63-64.

${ }^{15}$ Famoso violinista, descendente de moçambicanos.

${ }^{16}$ CARDOSO, 2002, p. 90.

17 Entrevista realizada em 3 fev. 2006, em Dili, Timor-Leste.

18 Marshall MCLUHAN, 1964.

${ }^{19}$ MCLUHAN, 1964, p. 342.

20 DE PASSAGEM por Timor-Leste, 2007.

${ }^{21} \mathrm{O}$ acesso a bens de consumo e serviços de telecomunicação ainda é muito oneroso para a população timorense em geral, como telefonia celular, televisão por satélite, antenas parabólicas e aparelhos receptores, e há que se considerar questões relativas a topografia e à precariedade da rede elétrica. Em 2002, o Relatório do Unicef apontava que apenas $30 \%$ dos lares possuíam um aparelho de rádio e $10 \%$ possuíam um televisor, cujo alcance não é extensivo a todo o território. tempo parou desde a chegada dos indonésios e da censura à língua portuguesa.

O escritor timorense Luis Cardoso ${ }^{14}$ lembra como esses sons importados penetravam na ilha através do rádio, o que se fazia sentir na época de sua juventude, antes de 1975:

Enquanto adormecia, ouvia lá longe os solos de violino do Abril Metam ${ }^{15}$ e as violas batendo o compasso certo duma valsa ou o tom jocoso e romântico dos brasileiros Teixeirinha e Roberto Carlos, mais a melosa country americana. Uma mistura de música de explodir os corações. [...] À noite juntava-me aos demais parentes em redor da telefonia para ouvir as encaloradas dedicatórias de amor [...].

Com a expansão da rede elétrica, essa influência, segundo o autor, tornou-se mais presente, o que evidencia o ecletismo de estilos: ${ }^{16}$

Grupos musicais eletrificados cantavam rock e faziam dançar o iêiê [...] como os Cinco do Oriente e UéLulik, que imitavam os Creedence Clearwater Revival, os Rolling Stones, os Beatles e cantavam algumas canções timorenses com batidas renovadas. Na rádio ouvia-se Amália [...]

O rádio também marcou a vida da comunicadora Filomena Soares, ${ }^{17}$ desde o primeiro aparelho receptor que recebeu de presente do pai, na infância:

Rádio é um aparelho, é um meio de comunicação. Mas se ele fosse uma pessoa, se ele fosse um homem, era meu marido - que eu gostei desde quando eu conheci [...]. Era muito difícil para nós para ter aparelho como rádio, gira-discos, gravadores. O meu pai conseguiu comprar um rádio. Quando passei, tirei a minha $4^{a}$ classe, meu pai ofereceu-me um rádio, um rádio para mim.

Esse poder do veículo de sensibilizar as pessoas há muito foi preconizado por McLuhan. ${ }^{18}$ De todas as mudanças ocorridas desde seus primórdios, o autor ${ }^{19}$ acrescenta o poder do rádio de "retribalizar" a humanidade e de reverter "o individualismo ao coletivismo", fenômeno que se inverte nos dias atuais, no Ocidente, com a escuta cada vez mais solitária do veículo através do fone de ouvido. Porém, em Timor-Leste, ainda subsiste a escuta coletiva. Conforme Luiza da Silva, ${ }^{20}$ é através do rádio que as informações se divulgam mais rapidamente: "A rádio é importante para dar informação à população sobre os principais fatos que estão acontecendo pelo país... Se algo acontece na capital, Dili, a população dos Distritos também poderá acompanhar".

É necessário enfatizar que é a classe popular, privada do acesso a outras mídias, ${ }^{21}$ que mais utiliza o rádio como 
22 Jean CAZENEUVE, 1965.

${ }^{23}$ Paul ZUMTHOR, 2000, p. 35-46. meio de informação. E esses ouvintes, que formam um "agrupamento a distância", representariam, como lembra Jean Cazeneuve, ${ }^{22}$ uma fusão de "nós", de vários "eus", o que nos remete à noção da escuta coletiva de Timor.

Essa ideia vem ao encontro da performance definida por Paul Zumthor ${ }^{23}$ como "uma ação complexa pela qual uma mensagem simultaneamente transitória é percebida aqui e agora"; assim "ela realiza, concretiza, faz passar algo que eu reconheço da virtualidade à atualidade". Zumthor explica também que performance evoca inevitavelmente a ideia da presença de um corpo; mas, às pulsações deste corpo, que possui seus ritmos (melodia, linguagem e gesto) e à sua emanação de voz, se agregam as pulsações de todos os outros corpos que o cercam, numa espécie de união ritual plena de energia poética, o que nos remete à magia do rádio.

\section{As mulheres timorenses: a voz, a memória $\Theta$ o ródio}

Em geral, em todos os povos colonizados por Portugal, a imagem que prevalece é a de uma mulher confinada ao lar, dedicada às tarefas domésticas, em constante aprendizado das atividades consideradas femininas, como cuidar da casa, dos filhos, da alimentação, e servir a todos, principalmente ao marido. Em Timor-Leste, nos próprios textos e ilustrações de manuais de aprendizado do português, notase essa divisão de tarefas bem presente, que se manifesta pela propagação de imagens consideradas representativas da vida das mulheres, contribuindo para consolidar os estereótipos.

Durante a colonização portuguesa, segundo Luís Filipe

${ }^{24}$ Luis Filipi THOMAZ, 1998, p. $670-$ 671. Thomaz, ${ }^{24}$ antigos militares desmobilizados se casaram com mulheres timorenses e iniciaram a cultura do café. Desse modo, reproduziu-se, no final do século XIX, "o modelo patriarcal da colonização de São Tomé e do Nordeste brasileiro do século $\mathrm{XVI}$, com a única diferença de utilizar mão-de-obra assalariada, em vez de escravos".

Assim, esses critérios preestabelecidos - e reforçados pelas relações colonialistas e típicas da sociedade ocidental dificultaram a visibilidade das mulheres. Para compreendermos, então, como vivem e transformam a realidade, é necessário mostrar o outro lado que extrapola o ponto de vista histórico, trazendo uma visão contemporânea, a partir da palavra delas próprias.

Alguns dos relatos que apresentamos são histórias únicas, pessoais, nas quais a palavra se destaca através da voz que fala no microfone, organiza a informação, reivindica mudanças, faz-se ouvir e narra. Assim, surgem alguns aspectos 
${ }^{25}$ Michelle PERROT, 1989, p. 9

${ }^{26}$ PERROT, 1989, p. 15

${ }^{27}$ PERROT, 1989, p. 17-18.
${ }^{28}$ Os lia na'in, senhores da palavra, são os porta-vozes da comunidade, chamados para representar o povo, a terra, a história e as tradições, entre si, para o mundo e transcendentalmente, tal qual os griots da tradição africana. ${ }^{29}$ MCLUHAN, 1964, p. 337-338.

${ }^{30}$ HERITIER, 2004, p. 64. sobre a condição feminina dominante no país: uma sociedade patriarcal onde ainda se vive em esferas culturais bem segmentadas e fechadas, protegidas do que vem de fora. Em muitas localidades, persiste uma distinção de gênero desde o nascimento, que continua com o casamento, a tradição do dote, a educação, a escolha profissional e tantas outras etapas da vida comunitária, marcada por leis consuetudinárias, que, aos poucos, vão se alterando com o acesso de mulheres aos estudos, a profissionalização, a participação social e os projetos comunitários.

Em seu texto sobre "Práticas da Memória Feminina", Michelle Perrot ${ }^{25}$ nos apresenta a constatação de que "a narrativa histórica tradicional reserva-lhes pouco espaço, justamente na medida em que privilegia a cena pública - a política, a guerra - onde elas pouco aparecem". Na história dos movimentos de mulheres contada pela referida autora, ${ }^{26}$ observa-se que os modos de registro de memórias femininas "estão ligados à sua condição, ao seu lugar na família e na sociedade", o que se configura como "uma memória do privado". E que essa memória é verbo, "está ligada à oralidade das sociedades tradicionais que lhes confiava a missão de narradoras da comunidade aldeã". O feminismo, desde seus primórdios, pontua Perrot, ${ }^{27}$ "desenvolveu uma imensa interrogação sobre a vida das mulheres obscuras" e, para a autora, "na falta de testemunhos escritos, buscou-se fazer surgir o testemunho oral". Daí a preocupação em tornar visível, acumular dados, evidenciar o papel das mulheres nos acontecimentos públicos, instituir lugares da memória, pois, enquanto "forma de relação com o tempo e com o espaço, a memória, como a existência da qual ela é o prolongamento, é profundamente sexuada".

Embora na tradição timorense a figura masculina é a que exerce essa função narrativa, ${ }^{28}$ a observação de Perrot encontra eco naquilo que o rádio tem de mais específico: a amplificação da palavra como um tambor tribal, como observou MacLuhan, ${ }^{29}$ imagem à qual o autor também acrescenta as marcas deixadas por esse meio de comunicação em tantos países onde a tradição oral ainda se faz presente:

A mensagem do rádio é uma mensagem de ressonância e de implosão unificada e violenta. Para a África, a Índia, a China e, mesmo, a Rússia, o rádio é uma força profundamente arcaica, um liame temporal com o passado mais longínquo e a experiência há muito soterrada na memória.

Ao longo dos anos, as mulheres foram silenciadas, pois, como explica Françoise Héritier, ${ }^{30}$ ao evocar Dominique Godineau, "a voz das mulheres é tumulto, ruído informe, 
31 PERROT, 1989, p. 15.

${ }^{32}$ Claude FILTEAU, 2009, p. 103.

${ }^{33}$ Tradução livre pela autora do original em francês.

${ }^{34}$ Entrevista realizada em 7 fev. 2006, em Dili, Timor-Leste.

${ }^{35}$ Comunidade dos Países de Língua Portuguesa. quando vem do povo [...] Incomoda com o seu barulho e o conteúdo não é ouvido". A palavra feminina, ressalta Perrot, ${ }^{31}$ sofreu um certo refluxo no século XIX, "desqualificada pelas formas de comunicação modernas, os sucessos retumbantes da escrita: correspondência, cartões-postais, diários". Ao mesmo tempo, perdeu-se uma função tradicional e houve ruptura de certas formas da memória.

Outros silêncios marcaram o curso de nossa história. Claude Filteau ${ }^{32}$ lembra que, na República de Platão, os artesãos foram excluídos do espaço políico comum porque se dedicavam exclusivamente ao trabalho. A palavra desses trabalhadores, "confinada ao espaço doméstico, fica longe da palavra audível, por consequência, longe da palavra que possui um valor político e confere uma humanidade àqueles que são reconhecidos". ${ }^{33}$ Há, portanto, muita semeIhança com o que ocorre com as mulheres que vivem silenciadas no lar.

Apesar das tradições, durante a guerrilha, mulheres como Rosa Alves, Filomena Soares, Genoveva e Inês Martins fizeram a diferença ao atuar tanto em atividades de comunicação quanto de mobilização popular em língua portuguesa. Após a independência, foram incentivadas a dar sua colaboração política e nos meios de comunicação social, incrementando a produção de emissões informativas, o que também representou um grande avanço no âmbito dos programas de desenvolvimento do milênio, que, entre outros temas, contempla a igualdade de oportunidades de gênero.

A jornalista Rosa Alves, ${ }^{34}$ que atua na Rádio Timor-Leste (RTL), preocupa-se em falar português, meio de acesso para a evolução profissional dos comunicadores. Através de seu relato, podemos notar as dificuldades que devem ser superadas:

Queria aperfeiçoar mais a língua portuguesa para ter mais conhecimento, pois há muito tempo não falamos [...]. Mas o problema sempre passa com os colegas que costumam falar a língua tétum, então é difícil de aprender. Os meus filhos, neste momento, aprendem língua portuguesa [...] mas eles, para falar, ainda é muito difícil porque há falta de estrutura das palavras [...] eles são da geração bahasa indonésio.

Ao viajar para a Alemanha, a fim de realizar cursos de aperfeiçoamento de rádio junto a outros comunicadores da CPLP, ${ }^{35}$ Rosa Alves sentiu-se identificada com os colegas que, como ela, sentem dificuldades para se expressar em português: Ýeu aprendi com eles sobre a língua, que é muito difícil, e eu também apresentei a eles que eu compreendo português, mas que para falar ainda é muito difícil para mim [...]. Esse fato, no entanto, não constitui obstáculo à 
${ }^{36}$ Entrevista realizada em $1^{\circ}$ fev. 2006, em Dili, Timor-Leste.
${ }^{37}$ Entrevista realizada em 3 fev. 2006, em Dili, Timor-Leste. continuidade de seu trabalho radiofônico. Como locutora, assume sotaques e particularidades para cumprir a missão de informar. Repórter aplicada, sempre se desloca com o gravador digital em punho, a fim de captar notícias pela cidade, que depois divulga no rádio, tanto em tétum como em português.

A coordenadora da ONG Lao Hamutuk, Inês Martins, ${ }^{36}$ produz um programa radiofônico dedicado às mulheres. Preocupada com o idioma, traz uma reflexão semelhante à de Rosa, enfatizando a necessidade de uma comunicação mais próxima da realidade de suas ouvintes:

Usamos muito a língua portuguesa durante a ocupação, mas, depois da independência, é muito difícil para nós nos comunicarmos. No ano 2002, criamos um programa de rádio e eu fui coordenar. Para os povos participarem deste movimento que estamos a desenvolver, transformamos o boletim escrito em programa de rádio popular, em inglês e bahasa indonésia, porque $60 \%$ das mulheres são analfabetas. Antes era inglês e tétum, mas era difícil o tétum porque elas não compreendiam. Então, mudamos para língua indonésia. Para comunicar, a maioria de Timor-Leste, de nossa geração, aprendeu o bahasa.

As notícias da RTL também são apresentadas pela locutora e jornalista Filomena Soares, ${ }^{37}$ que se sente satisfeita em dominar o português para apresentar seus programas:

Quando eu fiz programa no tempo da UNTAET e após a missão da UNTAET - e quando estive sozinha, eu faço programas em português... De manhãzinha [...] é cumprimentar os ouvintes que nos ouçam, não é? Eu sempre comecei: - Olá, bom dia, bem-vindos à nossa emissão de hoje. - Olá, caros ouvintes, muito bom dia! Sejam bem-vindos à nossa emissão. Na RTL é a mesma coisa: - Voltamos hoje de novo. Eu sempre troca. Mas, se for ler as notícias, quando apresento as notícias, sempre assim: - Rádio TimorLeste com o boletim de hoje. Filomena Soares nas notícias! Então, a gente começa: - Títulos das Notícias Principais [...] se for para terminar a programação, a gente diz assim: - Bom, caros ouvintes, por hoje é tudo - terminamos a nossa emissão. Ouvintes! Chegamos ao fim de mais uma edição em português. Para todos desejamos (se for no fim de semana) um bom fim de semana. Adeus, e até a próxima semana.

Ao gravarmos o relato de Filomena Soares, notamos que ela manifesta, como dom natural, o que se considera uma "estética da voz", expressividade única, trazida pelo modo de impostação no microfone, pela "performance"

1178 Estudos Feministas, Florianópolis, 21 (3): 1171-1187, setembro-dezembro/2013 
${ }^{38}$ Rudolf ARNHEIM, 1980, p. 89.

${ }^{39}$ MENEZES, 2007. p. 83. da emissão sonora. Para além dessa qualidade, ao demonstrar sua empatia com o rádio, consegue transmitir um carinho capaz de envolver os ouvintes das regiões mais isoladas, numa espécie de intimidade, que promove uma integração territorial carregada de emoções.

Um dos pioneiros nos estudos da estética radiofônica, Rudolf Arnheim, trouxe as primeiras reflexões sobre os recursos do rádio passíveis de criar o que chamou de "mundo acústico da realidade". Destacamos abaixo o que afirma sobre a criação de uma empatia entre locutor e ouvinte através da voz: ${ }^{38}$

É bastante significativa a impressão que determinadas vozes produzem nos radiouvintes, plenas de expressão, e que ele recebe como "a voz de alguém a quem não vê", mas cujo aspecto imagina, uma vez que o capta através de sua personalidade. Isto ocorre, sobretudo, com aquelas vozes que têm uma relação cotidiana com o radiouvinte e, para tanto, lhes são familiares: o locutor, o professor de ginásio, são pessoas bem conhecidas, não vozes conhecidas de desconhecidos. O complemento visual não faz falta.

A linguagem radiofônica, que reúne essa magia de sons emitidos pela voz - transmissora da palavra -, a música, ruídos e recursos não verbais, como o silêncio que pausa, promove aquilo que José Eugênio Menezes ${ }^{39}$ denomina de "vínculos sonoros", ou seja, uma aproximação com o ouvinte, advinda da linguagem e da natureza do rádio, que "no universo dos meios tem o seu lugar especial, não é um meio do passado, mas uma das mais importantes expressões da cultura do ouvir." E este ouvir nos remete às sonoridades das narrativas históricas e mitológicas dos antepassados, que, no curso de sucessivas gerações, foram deixando seu legado, preservando a memória enquanto manifestação do que, em um país subjugado, configurou-se como uma resistência cultural.

Nos estudos sobre a oralidade que nos legou, Zumthor traz significativas reflexões sobre a voz, remetendo-nos à emissão da palavra no rádio. O autor considera o veículo "uma mídia que suspende o excesso de imagens e tem a voz como um dos elementos básicos de sua linguagem sonora". Para ele, a voz, que possui qualidades simbólicas, tem sua materialidade situada entre o corpo e a palavra. Assim, entre o órgão que forma o som, este que dele emana, e a palavra assim pronunciada, se estabelece o que ele considera "uma circulação de sentidos que faz, a todo instante, de cada um destes três elementos o substitutivo possível dos dois outros".

Em sua obra Introdução à Poesia Oral, ${ }^{40}$ o conceito de palavra encontra ligações profundas com a voz, que, para o autor: "é a linguagem vocalizada, realizada fonicamente na emissão da voz". Embora afirme que ela, a voz, "ultrapassa 
41 ZUMTHOR, 2010, p. 13

42 ZUMTHOR, 2005, p. 94

${ }^{43}$ MCLUHAN, 1964, p. 344

${ }^{44}$ ZUMTHOR, 2000, p. 13

${ }^{45}$ ZUMTHOR, 1985, p. 8.

${ }^{46} \mathrm{~A}$ massificação, ou a cultura de massa, à qual nos referimos, estaria em relação direta com o aparato técnico e industrial da sociedade, onde se desenvolve, enquanto produção cultural, e pressupõe uma rede de meios de comunicação para se expandir e uma sociedade de consumo como mediador social. a palavra", o autor lembra que "na voz a palavra se enuncia como lembrança, memória-em-ato de um contato inicial, na aurora de toda vida e cuja marca permanece em nós um tanto apagada, como a figura de uma promessa". Desse modo, para além dessa evocação da memória, a voz tem o poder de ressignificar e personificar a palavra: ${ }^{41}$

A enunciação da palavra ganha em si mesma valor de ato simbólico: graças à voz ela é exibição e dom, agressão, conquista e esperança de consumação do outro; interioridade manifesta, livre da necessidade de invadir fisicamente o objeto de seu desejo; o som vocalizado vai de interior a interior e liga, sem outra mediação, duas existências.

A língua serviria apenas à manifestação dessa voz. $\mathrm{E}$, no rádio, ela, a voz, será amplificada pelo microfone, ${ }^{42}$ "cuja particularidade é a de conduzir a voz para além de seus limites", favorecendo o surgimento do que McLuhan ${ }^{43}$ chamou de "uma mesma câmara de eco", uma "aldeia global". No entanto, para o mesmo autor, "o rádio não efetua a homogeneização dos quarteirões da aldeia"; ele serviria para personalizá-la, reavivar a memória.

Para Zumthor, ${ }^{44}$ a voz também está intimamente associada à cultura de um povo, que, ao falar, cantar ou narrar, perpetua suas tradições:

Constitui, em toda cultura, um fenômeno central. Colocar-se no interior desse fenômeno é ocupar necessariamente um ponto privilegiado, a partir do qual as perspectivas contemplam a totalidade do que está na base dessas culturas, na fonte da energia que as anima, irradiando todos os aspectos de sua realidade.

No âmbito de uma tipologia das oralidades que nos apresenta, Zumthor ${ }^{45}$ inclui a oralidade mediatizada, que nos oferece o rádio, o disco e outros meios de comunicação e divulgação. Reforçando o conceito de "meios como extensões do homem", trazido por McLuhan, Zumthor lembra que, no rádio, "o microfone aumenta o espaço vocal e reduz as distâncias auditivas [e graças a ele] palavra e música tornamse verdadeiramente públicas".

Mesmo diante da perspectiva de haver, no futuro, meios de comunicação de massa em Timor-Leste, ${ }^{46}$ o espaço mágico do rádio - onde se projeta a voz que resiste aos tempos de muitas incertezas - parece ser um lugar propício às descobertas e transformações em curso no Timor, como revela emocionada a jornalista Filomena Soares:

Rádio é uma coisa principal também porque eu gostei da rádio. Mas não esperava que ia trabalhar na rádio. Quando aprendi a ouvir a rádio, eu chorei. Primeiro ouvi a música... a música que me traz aquela ima- 
${ }^{47}$ BARBERO, 2009. Notas pessoais da aula magna ministrada pelo autor em 17 de agosto de 2009, em São Paulo-SP. gem... Através da música a gente se comunica. A música também é um meio de comunicação. Então, traz aquela imagem, aquele sentimento: porque eu rendi e o meu irmão ficou. Os meus camaradas ficaram, eu rendi [...]. Eu sei conhecer música. Música a gente põe nos temas, né? Neste tema a gente põe essa música... Neste tema, a gente põe esta outra música... A gente conhece música, né? E com acompanhar com o tema. Quando pus músicas, as pessoas gostam e vem procurar a mim [...]. Apaixonaram por minha voz.

Esses sons de vozes femininas portadoras de novas palavras podem, assim, repercutir nas ruas e casas dos timorenses como sinais de um novo tempo que se vive através de múltiplas sonoridades.

Com a reorganização do movimento de mulheres e a criação de ONGs a partir do ano 2000 , o rádio voltou a ser um grande aliado da população timorense, e vários programas foram surgindo a partir de novos protagonistas.

Por trás de vozes femininas que dão vida ao veículo, vão sendo conhecidas cidadãs companheiras, que levam informação, reflexão, mensagens às famílias, se preocupam com a segurança de todos ou proporcionam algum encantamento a quem escuta. Ao falar de seus programas da hora do almoço, Filomena explica o seu modo de dedicar palavras amigas e músicas especiais, incentivando a harmonia entre homens e mulheres:

Por exemplo, o programa de descanso, ao meio-dia. Programa acompanha as pessoas, a família a almoçar. Programa de variedade. A gente dedica música para a família que está junto: - Para as pessoas que ainda estão a caminho: não acelere o carro, devagar se vai ao longe, ainda vai chegar, a família, a sua mulher está a espera para vocês almoçarem juntos...então a gente dedica música. [...] Nós não vamos por ritmos fortes... mas músicas suaves, mais calmas que as pessoas gostam. Ou pode ser um instrumental que é bonito também, que as pessoas gostam.

Essa aproximação com os ouvintes é uma das características mais marcantes do veículo em ambientes onde predomina a cultura oral. A visão que Martín-Barbero ${ }^{47}$ tem do rádio, além de sua longevidade, é a de que o veículo "organizou a nossa temporalidade (o cronos), o dia e a noite, o levantar, rezar, almoçar etc.". Essas afirmações podem ser transpostas para a realidade timorense, como evoca Inês Martins: "Hoje eu acho que o programa rádio é muito importante porque os povos, a maioria, são analfabetos, então para eles é difícil entender só o que publicamos por meio do boletim". 
${ }^{48}$ XINRAN, 2003, p. 180.

${ }^{49}$ MENEZES, 2007, p. 69.

${ }^{50}$ Entrevista realizada em 3 de fevereiro de 2006, em Dili, Timor-Leste.

${ }^{51}$ JerUSa PIRES FERREIRA, 1996, $\mathrm{p}$. 92.

1182 Estudos Feministas, Florianópolis, 21 (3): 1171-1187, setembro-dezembro/2013
O ativismo radiofônico de Inês vem ao encontro da experiência que a jornalista Xinran ${ }^{48}$ adquiriu na China, nos anos de 1980. Através dos assuntos que abordava em seus pro-gramas, a autora suscitava discussões sobre fatos sociais e encorajava as mulheres a falar sobre suas vidas, o que the permitiu conhecer inúmeras histórias de opressão, tortura e abandono, relatadas em cartas e depoimentos femininos transcritos em sua obra. As observações acima encontram eco nas ideias de Menezes ${ }^{49}$ sobre a linguagem dos locutores dos programas de rádio: "[Eles] estão continuamente rememorando efemérides, atualizando fatos antigos, comentando narrativas do cotidiano [...], transmitindo a sensação de que estamos 'localizados' em determinado 'lugar' e em determinado 'tempo'."

A receptividade por parte dos ouvintes transforma-se em força motivadora para a continuidade da missão comunicativa dos radialistas. O rádio, por sua instantaneidade e imediatismo, proporciona entre emissores e receptores uma troca mais direta e pontual. Na imaginação de Filomena Soares, ${ }^{50}$ ele exerce um poder quase sagrado - e milagroso de um templo, no qual sua presença viva de comunicadora, através da voz e da palavra, serve de alento aos que sofrem:

Quando a gente faz algum programa é logo um telefonema. Nessa altura, hora de descanso. [...] É importante o rádio, a participação das mulheres no rádio. Eu gosto muito da rádio. Televisão, não é muito porque televisão é sempre depois de um dia, a pessoa nos vê e ouvir. Ao passo que no rádio, não. Agora mesmo, a pessoa escuta-nos, né? Então... é a nossa presença na rádio é como uma coisa, é para animar as pessoas... No momento em que a gente aparece na rádio é como amigo. Parece que a nossa presença é capaz de trazer medicamentos para as pessoas que estão doentes e os doentes estão a nos ouvir. De vez em quando, com a nossa presença, eles curam, né? Quando eles gostam da pessoa, da locutora que eles gostam, com a nossa presença, de vez em quando, cura a doença deles. Portanto... quanto mais as mulheres - elas gostam de ouvir a voz das mulheres. Os homens, com certeza, as mulheres gostam... Mas, para as pessoas, como nós mulheres, que dominam as matérias que vamos apresentar, então vamos ter mais amigos, mais colegas, mais pessoas que nos gostam. Portanto, a rádio é importante para nós!

Em seu texto Voz, diálogo e semiosfera, Jerusa Pires Ferreira, ${ }^{51}$ ao discorrer sobre a literatura oral e as ideias de performance de Zumthor, trata da "função protetora da voz" e lembra que "cada sílaba é sopro, e a energia desse sopro ritmado pelo batimento do sangue, com o otimismo da matéria, 
52 Entrevista realizada em São Paulo, em 2 de fevereiro de 2009. converte a questão em anúncio, a memória em profecia [...]A voz, assim, se faz um acontecimento do mundo visual e tátil". Dessa maneira, o tempo quase mágico e criador de vínculos da passagem da voz pelo espectro radiofônico também pode ser compreendido como evocação de memórias de um outro tempo vivido, o de uma solidariedade ressignificada.

Contudo, para que essa proximidade entre a voz do locutor e o ouvinte frutifique e se transforme em uma cumplicidade, é preciso também conhecimento, sensibilidade e amor pela profissão, o que caracteriza o trabalho de Filomena:

Mas nós temos que trabalhar com toda dedicação. Temos que fazer bons programas. A voz é o fator principal. O conhecimento também é um fator principal. São dois fatores principais [...] porque a gente, depois, faz comentários [...]. Mas eu escrevo primeiro... então, a gente faz alguns comentários assim e depois a gente bota a música. A música boa assim. Com algum comentário. Então, vêm pessoas... parece que gostam do comentário que eu fiz... pessoas que gostam de mim, e vêm à minha procura.

A jornalista Rosa Alves levou para a RTL suas experiências do setor de informação da guerrilha. Sente-se plenamente satisfeita com suas atividades, tanto pela oportunidade que tem de se informar quanto de transmitir. O importante para ela é apresentar ao público as informações de fontes diversas ou, na sua maneira de dizer: "publicar ao povo", através da rádio, e trocar impressões com as autoridades e as pessoas mais simples também. Apesar de ter tido uma experiência na TV timorense, preferiu se dedicar exclusivamente ao rádio. Assim como Filomena, é nele que se aperfeiçoa e se sente mais gratificada: "é uma boa oportunidade de expressar informações que pratiquei nos passados", afirmou a jornalista.

Adalgisa Ximenes, ${ }^{52}$ assessora parlamentar e exdeputada, se encontra com muitas mulheres em locais distantes da capital e vê como o rádio e a língua tétum podem beneficiá-las na evolução de suas condições:

As minhas [mulheres] lá na montanha têm raciocínio, só que não sabem escrever. A nossa língua tétum pode ajudar muito porque essa língua não é escrita, é a língua mais ouvida. Se nós temos a comunicação através da media rádio, todos os dias elas sintonizam, podem fazer mudança.

As transformações sociais serão notadas com o passar do tempo e a continuidade deste trabalho, e, nesse sentido, as ideias de Adalgisa vão ao encontro das reflexões de Inês Martins sobre a necessidade de informar mais regularmente as mulheres: 
${ }^{53}$ Entrevista realizada em $1^{\circ}$ de fevereiro de 2006, em Dili, TimorLeste.
Há pouco tempo tivemos um plano estratégico, o que agora estamos a discutir. Então nós queremos este programa quatro vezes por mês. Às vezes nós temos dificuldade em atender isso. Então, nós queremos, trabalhamos junto com outras organizações que têm também um programa sobre as mulheres ou sobre as leis. Então eles podem utilizar também este programa. Nós estamos a procurar.

A ONG La'o Hamutuk atua com profissionalismo, tentando adequar os temas abordados no rádio às necessidades das mulheres que vivem mais distantes. Inês Martins trabalha com pesquisa-ação para o boletim e, a partir do impresso, desenvolve com sua equipe, pouco a pouco, as pautas e 0 melhor modo de apresentá-las no rádio: ${ }^{53}$

Queremos discutir e aprender e falar mais com as colegas que têm mais experiência com rádio. [...] rádio também é importante instrumento para educar as mulheres de Timor-Leste. A maioria tem capacidade limitada. A educação também pode se fazer por meio de rádio - e a ação também: a saúde e a educação é muito importante para as mulheres. Com a educação o que as mulheres podem desenvolver? Também é importante a saúde. Então, para elas poderem saber que têm direitos e conhecer a si mesmos, faz uma educação... O que que eles vão tocar nos programas para dar benefício às mulheres? Na média, no campo, o único acontecimento é de relação sexual. Deveria descrever como as mulheres fazem parte deste acontecimento.

A equipe radiofônica que coordena já se preparou para lidar com a parte técnica e hoje mantém duas pessoas com capacidade para assegurar as gravações e edições sonoras.

Adalgisa Ximenes apenas ouve rádio pela manhã, aos sábados e às segundas-feiras, mas colabora no que é possível quando é interpelada: ela já foi entrevistada em um programa feminino. Satisfeita com sua participação, ela acredita que é salutar esse diálogo entre as próprias mulheres:

As mulheres têm mais sensibilidade para tratar das questões femininas no rádio. Eu acho... porque as mulheres de Timor têm muita responsabilidade... Quase todas as mulheres timorenses têm responsabilidade doméstica. E este programa queria saber mais as atividades das mulheres relacionadas com a vida de trabalho, política e a vida, educação [...]. Esse programa foi planejado por um padre timorense e é específico para a questão das mulheres. O nome do programa era Bua Malos, era a areca e a folha que

1184 Estudos Feministas, Florianópolis, 21 (3): 1171-1187, setembro-dezembro/2013 


\begin{abstract}
${ }^{54}$ A masca é popularmente chamada de "mama", composta de soda cáustica, nozes de uma planta chamada areca, envoltas em folhas de betel. O "ahu" (cal), foIhas de betel - "malus" e a noz de areca - "bua", têm efeito narcótico, tingindo a boca de vermelho. Segundo Moser (2004, não paginado), "mascar a noz de areca é costume dos mais antigos entre os Povos da Ásia. Esse exercício garante o tanto de energia para chegar ao fim do dia. Mas, o ritual possui também razões sociais e culturais. Mascar a noz de bétel é como definir a pertença ao mundo adulto da maturidade. A noz de bétel re presenta a força generativa da muIher; o fruto da arequeira, a força vital do homem; a cal, a semente da reprodução. O processo do 'mascar' provoca abundante salivação vermelha. Acredita-se que cuspir a saliva, é como devolver à terra o sangue do parto. [...] Mascar o bétel proporciona doce ebriedade, quem sabe a memória de remotas jornadas pré-históricas."

55 MENEZES, 2007, p. 85.
\end{abstract}

juntava com a areca para mastigar. ${ }^{54}$ Não sei por que levou este nome, mas o bua malos, muitas vezes, representa o símbolo da amizade entre os timorenses.

\section{Considerações}

Levando-se em conta que o encargo de mãe e educadora tem um grande peso na vida das timorenses, que têm contato mais direto com os filhos, organizam e dinamizam as relações familiares, o aporte das comunicadoras adquire ainda maior relevância quando se constata que elas representam uma especial fonte de mediação entre o lar e a vida profissional.

Se, como observa Menezes, 55 "o rádio, entre as mídias sonoras, atinge dimensões profundas dos cidadãos; possibilita uma forma ritual de se lidar com o passado comum e com o futuro comum", as mulheres estão preparando algo de novo que poderá ser materializado num breve tempo.

Na voz das mulheres, circulam informações e esperanças, e também outras formas de se socializar novos ideais. É esse uso da palavra que faz com que as mulheres atuem como agentes de transformação social sem delegar unicamente ao homem o poder da palavra. Isso contribui para com a construção cultural da identidade de gênero no espaço público, que pode operar grandes transformações.

Espera-se, durante o processo transformador de uma identidade nacional timorense, que todas as singularidades da ilha continuem a ser respeitadas, pois elas se manifestam em locais parcialmente isolados onde imperam diferenças significativas. Nesse sentido, há que se considerar o potencial do rádio e o protagonismo das mulheres na divulgação da diversidade e na transmissão de toda a riqueza cultural que se preserva pela oralidade em diversos idiomas. Enquanto meio privilegiado de divulgação da palavra, o veículo vai muito além do que permite a evolução técnica de apenas cobrir todo o território: ele atua de modo quase ritual na escuta coletiva, dentro de uma dinâmica social que perpassa a oficialidade nas extensões da voz mediadora de seus atores.

\section{Referências}

AMARANTE, Maria Inês. Guerrilheiras da Palavra. Rádio, oralidade e mulheres em resistência no Timor-Leste. 2010, 278 p. Tese (Doutorado em Comunicação e Semiótica) Pontifícia Universidade Católica de São Paulo, São Paulo.

"Rádio Comunitária em Timor-Leste: os meios de comunicação em novos tempos de cidadania". Contracampo - Revista do Programa de Pós-Graduação em Comunica- 
ção - UFF, Instituto de Arte e Comunicação Social, n. 15, p. 165-181, 2. semestre 2006.

ARNHEIM, Rudolf. Estética Radiofônica. Trad. língua espanhola de Manuel Figueiras Blanch. Barcelona: Ediçõos Gustavo Gili, 1980.

BORGES, Reinaldo. "Community Radio in Conflict Situations Timor-Leste: Resilience and Hope." In: AMARC 8: Voices for a Better World. Asia Pacific Report. 8th World Conference of Community Radio Broadcasters. Kathmandu, Nepal, Feb. 2003. p. 21-27. Disponível em: <www.obsmedia.amarc. org/files/AMARCAsiaPacificReport.pdf>. Acesso em: 30 abr. 2010.

CARDOSO, Luís. Crônica de uma travessia: a época do AiDik-Funam. Lisboa: Dom Quixote, 2002.

CAZENEUVE, Jean. Sociologie de la Radio-Télévision. Paris: Presses Universitaires de France, 1965. (Collection "Que Sais-Je?" n. 1026).

DE PASSAGEM por Timor-Leste. Produção e Tradução: Verbo Filmes, Carlos Alberto da Silva, SVD - Fernando Doren, SVD, Direção e edição: Cireneu Kuhn, SVD. São Paulo, Agosto 2007. 1 DVD.

FILTEAU, Claude. "Miron et le partage du sensible." Armand Colin, Littérature. n. 153, p. 102-113, 2009. Disponível em: <http://www.cairn.info/revue-litterature-2009-1-p102.htm>. Acesso em: 15 fev. 2010.

GUEDES, Armando Marques. "Pensar Timor, a Indonésia e a Ásia do Sudeste". Janus 2002, p. 2-6. Disponível em: <www.janusonline.pt>. Acesso em: 20 fev. 2010.

HERITIER, Françoise. Masculino, feminino: dissolver a hierarquia. Lisboa: Instituto Piaget, 2004. (Coleção Epistemologia e Sociedade, 226).

HULL, Geoffrey. Manual de Língua Tétum para Timor-Leste. Austrália: Sebastião A. da Silva Project, 2001.

MARTINS, Inês. Entrevista concedida à autora em 1 fev. 2006, em Dili, Timor-Leste. 1 Cassete.

MARTINS, Maria Genoveva da Costa. Entrevista concedida à autora em 6 fev. 2006, em Dili, Timor-Leste. 2 Cassetes.

MATTOSO, José. A dignidade. Konis Santana e a Resistência Timorense. Lisboa: Temas e Debates, Actividades Editoriais Ltda/Fundação Mário Soares, 2005.

MCLUHAN, Marshall. Os meios de comunicação como extensões do homem (understandind media). São Paulo: Cultrix, 1964.

MENEZES, José Eugenio de Oliveira. Rádio e Cidade: vínculos sonoros. São Paulo: Annablume, 1. ed., 2007.

MOSER, Chico (Pe.) "Ao Leste, rostos e semblantes". 10 out. 2004. Timor-Leste: Dili. Disponível em: <http://www.timorcrocodilo voador.com.br/olhar-crocodilo-chicomoser-rosto.htm>. Acesso em: 17 fev. 2010.

1186 Estudos Feministas, Florianópolis, 21(3): 1171-1 187, setembro-dezembro/2013 
PALERMO, Vera Lúcia Ir. Entrevista concedida à autora em 31 de maio de 2009, em São Paulo, Brasil. Meio digital.

PERROT, Michelle. "Práticas da Memória Feminina". Revista Brasileira de História, São Paulo: ANPUH/Marco Zero, v. 9 n. 18, ago./set. 89, p. 9-18, 1989.

PIRES FERREIRA, Jerusa. "Sermão, Vieira, Performance". Asas da Palavra - Revista de Letras. Belém: Unama, v. 10, n. 23, 2007, semestral, p. 160-169.

. "Voz, diálogo e semiosfera". In: SILVA, Ignacio Assis (Org.). Corpo e sentido: a escuta do sensível. São Paulo: Editora da Universidade Estadual Paulista, 1996. (Seminários e Debates) p. 91-95.

SOARES, Filomena (MENA). Entrevista concedida à autora em 3 fev. 2006, em Dili, Timor-Leste, 2 Cassetes.

TIMOR-LESTE. A Resistência Timorense em documentos. Fundação Mário Soares (Fado Filmes), CD-ROM, 2004.

THOMAZ, Luís Felipe F. R. De Ceuta a Timor. Portugal: DIFEL Difusão Editorial S. A., 2. ed., 1998.

XIMENES, Adalgisa Soares. Entrevista concedida à autora em 2 de fevereiro de 2009, em São Paulo, Brasil. Meio digital.

XINRAN. As boas mulheres da China. Vozes ocultas. São Paulo: Companhia das Letras, 2003.

ZUMTHOR, Paul. Introdução à Poesia Oral. Trad. Jerusa Pires Ferreira; Maria Lúcia Diniz Porchat; Maria Inês de Almeida. Belo Horizonte: Editora UFMG, 2010.

Performance, Recepção, Leitura. Tradução de Jerusa Pires Ferreira e Suely Fenerich. São Paulo: EDUC, 2000.

"Permanencia de la Voz." In: El Correo. UNESCO. De La palabra viva a la escrita, ano 38, n. 8, Agosto 1985, p. 4-8.

[Recebido em 15 de outubro de 2012 , reapresentado em 6 de maio de 2013

e aceito para publicação em 21 de junho de 2013]

\section{Guerrilla Word: Women in Radio in East Timor}

Abstract: This article clipping of the author's doctoral thesis, shows the social role of radio in East Timor, as well as the role of women communicators guerrrilheiras once, since the country's independence. Although the presence of women in the media Timorese is still quite timid and there is a need to overcome several barriers, including the use of the Portuguese language, they emphasize the importance of this participation and recognition of the working spaces in newly conquered radio. Among reflections on the voice and word environments "mediatized orality," will reveal the cultural aspects of a people who are seeking to adapt themselves into a new reality without giving up their traditions. The research was conducted in the field, between 2005-06 and materialized through documentary surveys, literature and interviews (life story and witness reports).

Key Words: Radio; Women Memory; Voice and Orality; Portuguese Language; East Timor. 